\title{
Co-seismic landslide topographic analysis based on multi-temporal DEM-A case study of the Wenchuan earthquake
}

\author{
Zhikun Ren ${ }^{1 *}$, Zhuqi Zhang ${ }^{1}$, Fuchu Dai ${ }^{2}$, Jinhui Yin ${ }^{1}$ and Huiping Zhang ${ }^{1}$
}

\begin{abstract}
Hillslope instability has been thought to be one of the most important factors for landslide susceptibility. In this study, we apply geomorphic analysis using multi-temporal DEM data and shake intensity analysis to evaluate the topographic characteristics of the landslide areas. There are many geomorphologic analysis methods such as roughness, slope aspect, which are also as useful as slope analysis. The analyses indicate that most of the co-seismic landslides occurred in regions with roughness, hillslope and slope aspect of $>1.2,>30$, and between 90 and 270, respectively. However, the intersection regions from the above three methods are more accurate than that derived by applying single topographic analysis method. The ground motion data indicates that the co-seismic landslides mainly occurred on the hanging wall side of Longmen Shan Thrust Belt within the up-down and horizontal peak ground acceleration (PGA) contour of 150 PGA and 200 gal, respectively. The comparisons of pre- and postearthquake DEM data indicate that the medium roughness and slope increased, the roughest and steepest regions decreased after the Wenchuan earthquake. However, slope aspects did not even change. Our results indicate that co-seismic landslides mainly occurred at specific regions of high roughness, southward and steep sloping areas under strong ground motion. Co-seismic landslides significantly modified the local topography, especially the hillslope and roughness. The roughest relief and steepest slope are significantly smoothed; however, the medium relief and slope become rougher and steeper, respectively.
\end{abstract}

Keywords: Co-seismic landslide; Topographic; PGA; Multi-temporal DEM; Wenchuan earthquake

\section{Introduction}

It has been commonly accepted that steep topography are of high landslide frequency in active orogenic region. The co-seismic landslides usually occurred in active orogenic regions, which are one of the major secondary nature hazards related to strong earthquakes (Harp and Jibson 1996; Gallousi and Koukouvelas 2007; Owen et al. 2008; Ren and Lin 2010; Dai et al. 2011a). In some cases, co-seismic landslides even produce more serious human loss and damages than the earthquake itself. Thus, the coseismic landslides have fundamental influence on human life and seismic design of buildings etc. It has been noticed that transportation and deposition of the landslide materials will also have fundamental impact on the topographic

\footnotetext{
* Correspondence: rzk@ies.ac.cn

${ }^{1}$ State Key Laboratory of Earthquake Dynamics, Institute of Geology, China Earthquake Administration, Beijing 100029, China

Full list of author information is available at the end of the article
}

evolution (Meng et al. 2006; Godard et al. 2010; Ouimet, 2010; Hovius et al. 2011; Parker et al. 2011). Contemporary, the topographic conditions will also affect the susceptibility of landslides (Jibson et al. 2000; Dai and Lee 2002; Korup et al. 2007). A variety of approaches have been used in slope instability analysis, which has been one of the most important topographic features in detecting susceptible landslide areas (Dai and Lee 2002; Korup et al. 2007; Ren and Lin 2010; Chuang and Fabbri 2008). With the development of Geographical Information Systems (GIS), numerous quantitative topographic analysis approaches have developed in recent years. Topographic roughness, slope aspect and hillslope are the most commonly used features in tectonic geomorphologic and landslide-related studies (e.g., Dai and Lee 2002; Casson et al. 2005; Zhang et al. 2011; Ren and Lin 2010). The lithologic units and concentrations of the co-seismic landslides induced by Wenchuan earthquake 
have been analyzed in detail (Dai et al. 2011a). In this paper, we will mainly focus on the topographic characteristics of the co-seismic landslides. The shaking intensity is another important parameter that has been thought to be related to co-seismic landslides as well as sand liquefactions (Harp and Wilson 1995; Murphy et al. 2002; Meunier et al. 2007; Wang et al. 2011). In this study, we also use the open accessed strong motion records to analyze the relationship between Wenchuan earthquake triggered co-seismic landslides and the peak ground acceleration (PGA) distribution, which is distributed by CSMNC (China Strong Motion Networks Center), IEMCEA (Institute of Engineering Mechanics, China Earthquake Administration).

The occurrence of $2008 \mathrm{Mw} 7.9$ Wenchuan earthquake provides a valuable opportunity to verify the accuracy of multiple approach analyses involving variable topographic analyses and shaking intensity. The landslide areas are validated using the pre-earthquake high-resolution digital elevation model (DEM) data derived from 1:50,000 topographic maps. The analyses indicate that the co-seismic landslides are closely correlated to the topographic conditions as well as the shaking intensity. The topographic effects of the Wenchuan earthquake are also analyzed based on post-earthquake DEM data derived from stereo pair of IRS-P5 (Indian Remote Sensing Satellite) remote sensing images by comparing with pre-earthquake DEM.

\section{Study area}

The Longmen Shan region is one of the steepest margins of the Tibetan Plateau accompany with almost $5000 \mathrm{~m}$ altitude decrease across the margin within $50 \mathrm{~km}$ distance (Burchfiel et al. 1995, 2008; Chen and Wilson 1996, Figure 1). It is also an active orogen whose activity has been largely underestimated due to the less crustal shortening and low slip rates of the major faults within it, as revealed by low geodetic slip rates, shortening rates (King et al. 1997; Chen et al. 2000; Zhang et al. 2004; Gan et al. 2007) and geological slip rates (Densmore et al. 2007; Zhou et al. 2007). There are four major active fault systems within the Longmen Shan Thrust Belt: Wenchuan-Maowen, Yingxiu-Beichuan, GuanxianAnxian and Qingchuan fault systems (Burchfiel et al. 1995, 2008; Densmore et al. 2007; Zhou et al. 2007). It has been reported that the Wenchuan earthquake ruptured the Yingxiu-Beichuan and Guanxian-Anxiang faults

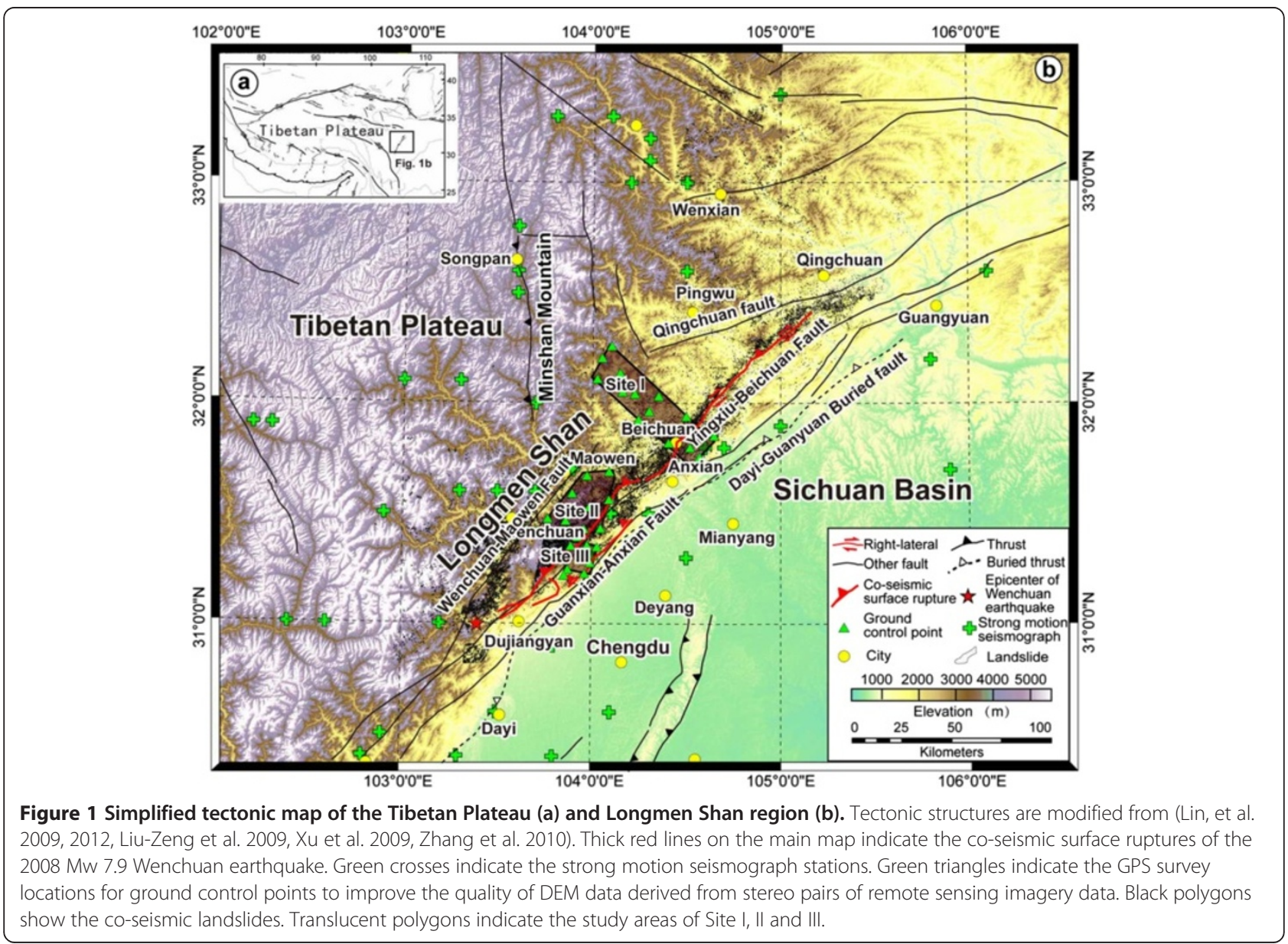


Table 1 Stereo pairs IRS-P5 Imagery used in post-earthquake DEM derivation

\begin{tabular}{llll}
\hline No. & Path & Row & Date \\
\hline 1 & 659 & 250 & 20080603 \\
2 & 659 & 251 & 20080603 \\
3 & 659 & 252 & 20080603 \\
4 & 659 & 253 & 20080603 \\
5 & 659 & 254 & 20080603 \\
\hline
\end{tabular}

(Lin et al. 2009; Xu et al. 2009; Liu-Zeng et al. 2009; Zhang et al. 2010), although it is still ambiguous that whether the Qingchuan fault is ruptured (Lin et al. 2012). A large amount of co-seismic landslides were triggered on the steep slope regions accompany with the co-seismic deformations (e.g. Ren and Lin, 2010; Yin et al. 2010; Dai et al. 2011a,2011b; Parker et al. 2011; Tang et al. 2011), which significantly changed the local topography. The co-seismic landslides mainly distributed in a corridor that bounds the co-seismic surface rupture, with major portion on the hanging wall side (Ren and Lin 2010; Yin et al. 2010; Godard et al. 2010; Ouimet 2010; Dai et al. 2011a, 2011b). Thus, the earthquake triggered deformation and landslides can dominate local erosion and landscape evolution in Longmen Shan region (Meng et al. 2006), as in other active orogen in the world (Hovius et al. 2011; Mackey and Roering 2011). Therefore, the co-seismic landslides of the Wenchuan earthquake should be controlled by the topographic conditions and will consequently affect the local topographic evolution in Longmen Shan region.

\section{Data and methods}

\section{Data acquirement}

With the development of GIS techniques, recent quantitative topographic analyses are usually based on DEM data. Previous studies suggest that the DEM data derived from stereo pair of remote sensing imagery data is favorable in landslide detection (Casson et al. 2005). The Indian Remote Sensing Satellite P5 (IRS-P5) carries two Panchromatic cameras (PAN fore and PAN after), which is favorable for deriving post-earthquake DEM. In this study, we derived a $5 \mathrm{~m}$ resolution DEM using the stereo pairs of $2.5 \mathrm{~m}$ resolution IRS-P5 imagery data. Three representative sites (Site I-III) were selected for DEM derivation, which have no cloud coverage at the time of imagery acquisition (Table 1). To improve the DEM quality, we also applied field ground control points (GCP) survey using Trimble R8 GPS (Figure 1). Finally, we derived the DEM using the GCP points, Rational Polynomial Coefficient (RPC) camera model (Tao and $\mathrm{Hu} 2001$ ) and tie points between the Pan fore and Pan after imagery. The checkpoints indicate that the error of the post-earthquake DEM is usually less than $1.5 \mathrm{~m}$ (Tables 2 and 3), which is precise enough for landslide topography analysis. Because there are no pre-earthquake stereo pairs of remote sensing imagery data available, the pre-earthquake DEM data are derived from the best data we can get-the 1:50,000 topographic maps. The topographic maps are surveyed using stereo pairs of aerial photograph with sufficient ground control points (GCP) by National Administration of Surveying, Mapping and Geoinformation of China (NASMGC) in 1970s.

Table 2 Elevation precision of topographic map derived pre-earthquake DEM

\begin{tabular}{llllll}
\hline No. & Longitude $\left({ }^{\circ}\right)$ & Latitude $\left({ }^{\circ}\right)$ & GPS_Elevation $(\mathbf{m})$ & DEM_Elevation $(\mathbf{m})$ & Error $(\mathbf{m})$ \\
\hline 1 & 106.023 & 32.9621 & 616.749 & 620.08234 & 3.3333364 \\
2 & 105.457 & 32.0184 & 678.851 & 682.28235 & 3.4313486 \\
3 & 103.435 & 32.9307 & 3587.7 & 3583.9824 & -3.7175781 \\
4 & 102.501 & 32.7856 & 3471.93 & 3462.3823 & -9.5476758 \\
5 & 104.571 & 32.4053 & 1312.77 & 1312.4823 & -0.2877002 \\
6 & 104.831 & 32.1819 & 1068.06 & 1064.7823 & -3.2776514 \\
7 & 104.444 & 31.8019 & 1002.18 & 1002.1824 & 0.0023731 \\
8 & 103.166 & 32.075 & 2957.83 & 2948.6824 & -9.1476269 \\
9 & 104.782 & 31.4865 & 489.381 & 484.88232 & -4.4986758 \\
10 & 104.187 & 31.3529 & 571.82 & 571.2334 & -0.5866016 \\
11 & 104.441 & 31.1571 & 483.26 & 484.68231 & 1.422312 \\
12 & 104.077 & 30.732 & 490.226 & 494.68231 & 4.456312 \\
13 & 103.41 & 30.415 & 559.666 & 550.9823 & -8.6837002 \\
14 & 106.034 & 30.8042 & 295.216 & 299.77786 & 4.5618625 \\
\hline
\end{tabular}

The mean elevation error is calculated to be $\pm 4.1 \mathrm{~m}$. 
Table 3 Elevation precision of imagery derived post-earthquake DEM

\begin{tabular}{|c|c|c|c|c|c|}
\hline No. & Longitude $\left({ }^{\circ}\right)$ & Latitude $\left({ }^{\circ}\right)$ & GPS_Elevation(m) & DEM-Elevation(m) & Error $(m)$ \\
\hline 1 & 103.89948 & 31.34582 & 1390.878 & 1393.403 & -2.525 \\
\hline 2 & 103.96341 & 31.22905 & 876.761 & 874.376 & 2.385 \\
\hline 3 & 104.02967 & 31.34853 & 798.949 & 799.126 & -0.177 \\
\hline 4 & 103.99306 & 31.27809 & 738.503 & 737.37 & 1.133 \\
\hline 5 & 103.9768 & 31.35489 & 1090.177 & 1090.542 & -0.365 \\
\hline 6 & 104.53361 & 31.87152 & 599.059 & 598.938 & 0.121 \\
\hline 7 & 104.22619 & 32.03414 & 1104.028 & 1103.25 & 0.778 \\
\hline 8 & 104.35132 & 31.95228 & 1470.297 & 1467.909 & 2.388 \\
\hline 9 & 104.4132 & 31.8329 & 942.5816 & 940.137 & 2.4446 \\
\hline 10 & 104.58483 & 31.82802 & 571.4206 & 572.47 & -1.0494 \\
\hline 11 & 104.52359 & 31.778 & 806.9447 & 805.641 & 1.3037 \\
\hline 12 & 103.942 & 31.31536 & 942.3366 & 946.256 & -3.9194 \\
\hline
\end{tabular}

The elevation mean error is calculated to be $\pm 1.5 \mathrm{~m}$.

Previous DEM precision check tables show the mean error of the pre-earthquake DEM is $\pm 4.1 \mathrm{~m}$, and median error is $\pm 3.6 \mathrm{~m}$; the mean error of the post-earthquake DEM is $\pm 1.5 \mathrm{~m}$, and mean elevation error is $\pm 1.2 \mathrm{~m}$.
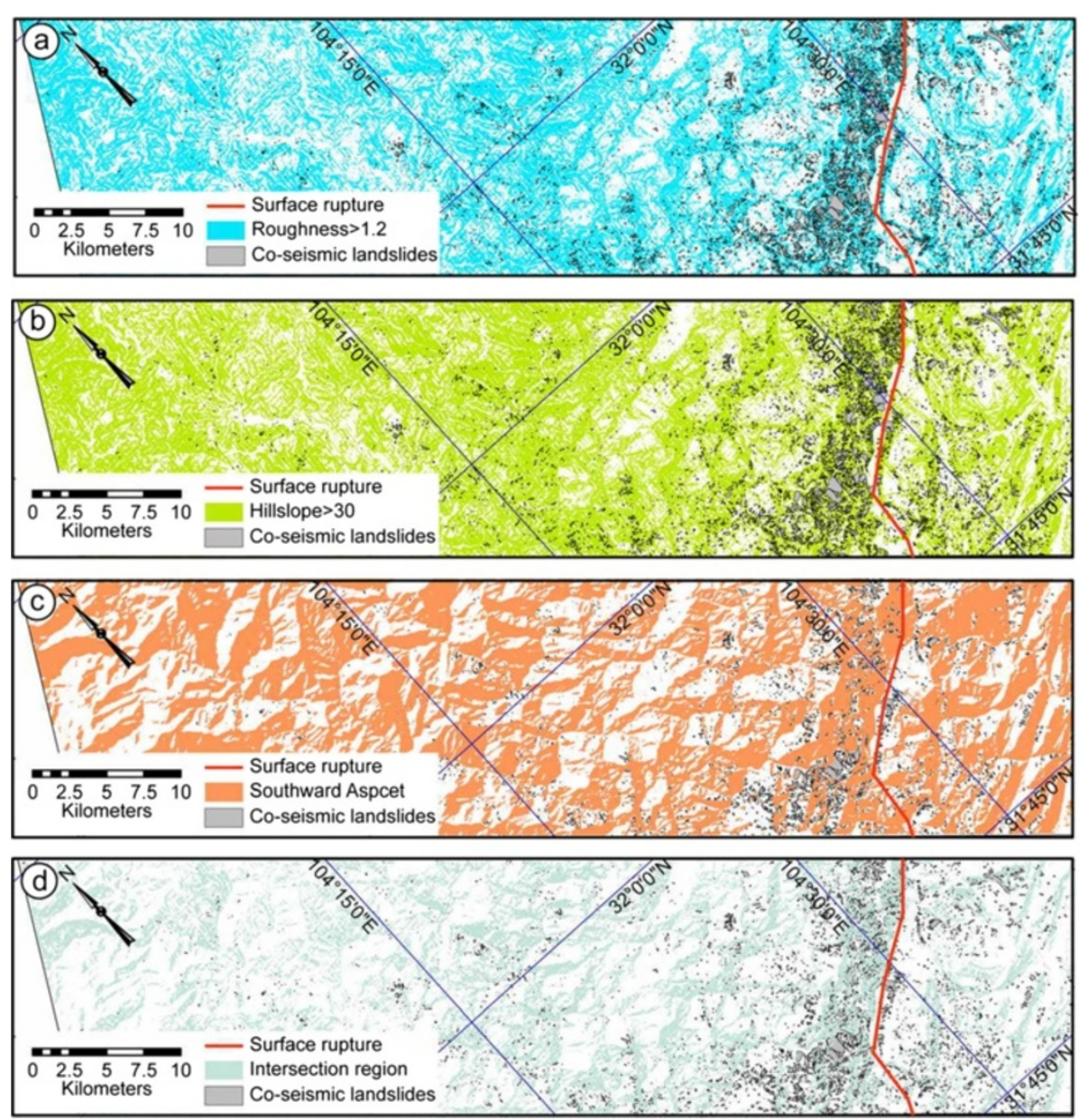

Figure 2 Topographic features of Site I. The roughness (a), hillslope (b), slope aspect (c) distribution of Site I based on pre-earthquake DEM data; and the intersection region of the above three regions (d) by applying thredholds $>1.2$ (a), $>30$ (b) and between 90 and 270 (c). The maps show the landslide mainly occurred in the derived regions. 


\section{Methods}

\section{Topographic analyses}

Roughness To express the ragged topography, roughness is a widely-used factor in topographic studies. Roughness is defined by the ratio between the surface area and projected area. It is usually obtained by averaging the roughness value over an area of $3 \times 3$ pixel size. By running a test to determine the best threshold on the balance of the percentage of landslides within the derived region and corresponding area, the threshold of 1.2 for roughness could be determined (Figures 2, 3 and 4). It shows that most of the landslides occurred in regions with roughness larger than 1.2, i.e., the threshold of 1.2 is the most effective value in landslide detection. We also compared the pre- and post-earthquake roughness within the landslide area. It indicates that the medium topographic roughness significantly increased after earthquake. The roughest relief is also smoothed by the Wenchuan earthquake (Figure 5(b)).

Hillslope Slope instability analysis has been one of the most important topographic analyses regarding landslide susceptibility. It has been testified that steep slope areas are prone to landslides (Burbank et al. 1996; Densmore et al. 1998; Dai and Lee 2002). The co-seismic landslides of the Wenchuan earthquake mainly distribute in regions with slopes larger than $30^{\circ}$ on pre-earthquake DEM (Ren and Lin 2010; Figures 2, 3 and 4). Thus, we analysis the relationship between the co-seismic landslides and slope distribution by applying a threshold of $30^{\circ}$ on the slope distribution map (Figures 2, 3 and 4, Table 4). In order to detect the slope changes produced by the co-seismic landslides, we compared the slope distribution pre- and post-earthquake within the landslide area. It indicates that the medium slope significantly increased after earthquake, which indicates that the topography is becoming steeper. However, the steepest slopes decreased after earthquake, which indicates that the Wenchuan earthquake also smoothed the pre-earthquake steepest slopes (Figure 5(a)).

Slope aspect The slope aspect is the expression of horizontal direction that a mountain slope faces. Due to the exposure to sunrays, the slope aspect has fundamental
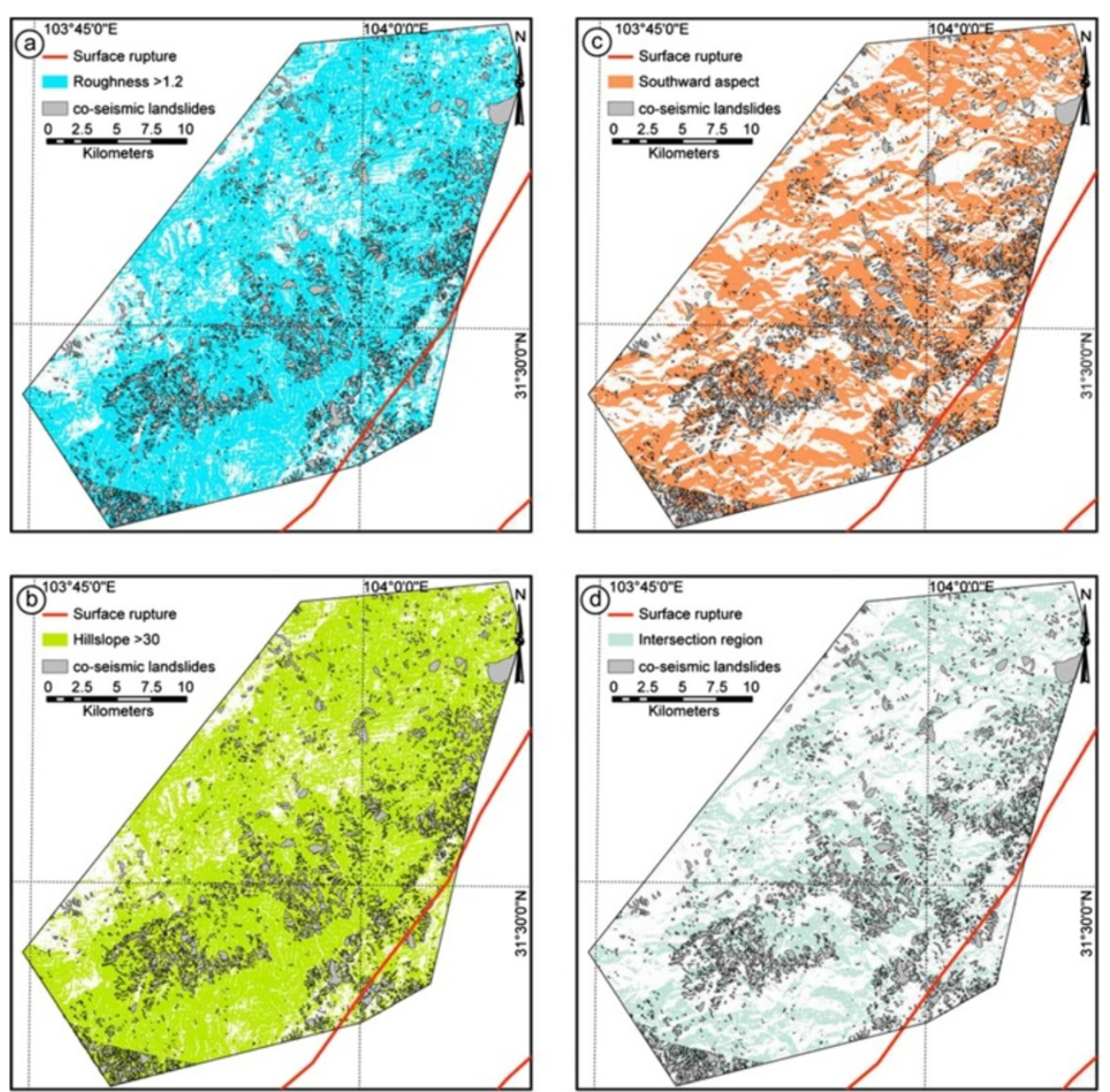

Figure 3 Topographic features of Site II. The roughness (a), hillslope (b), slope aspect (c) distribution of Site II based on pre-earthquake DEM data; and the intersection region of the above three regions (d) by applying thresholds >1.2, between 90 and 270, and 30. 

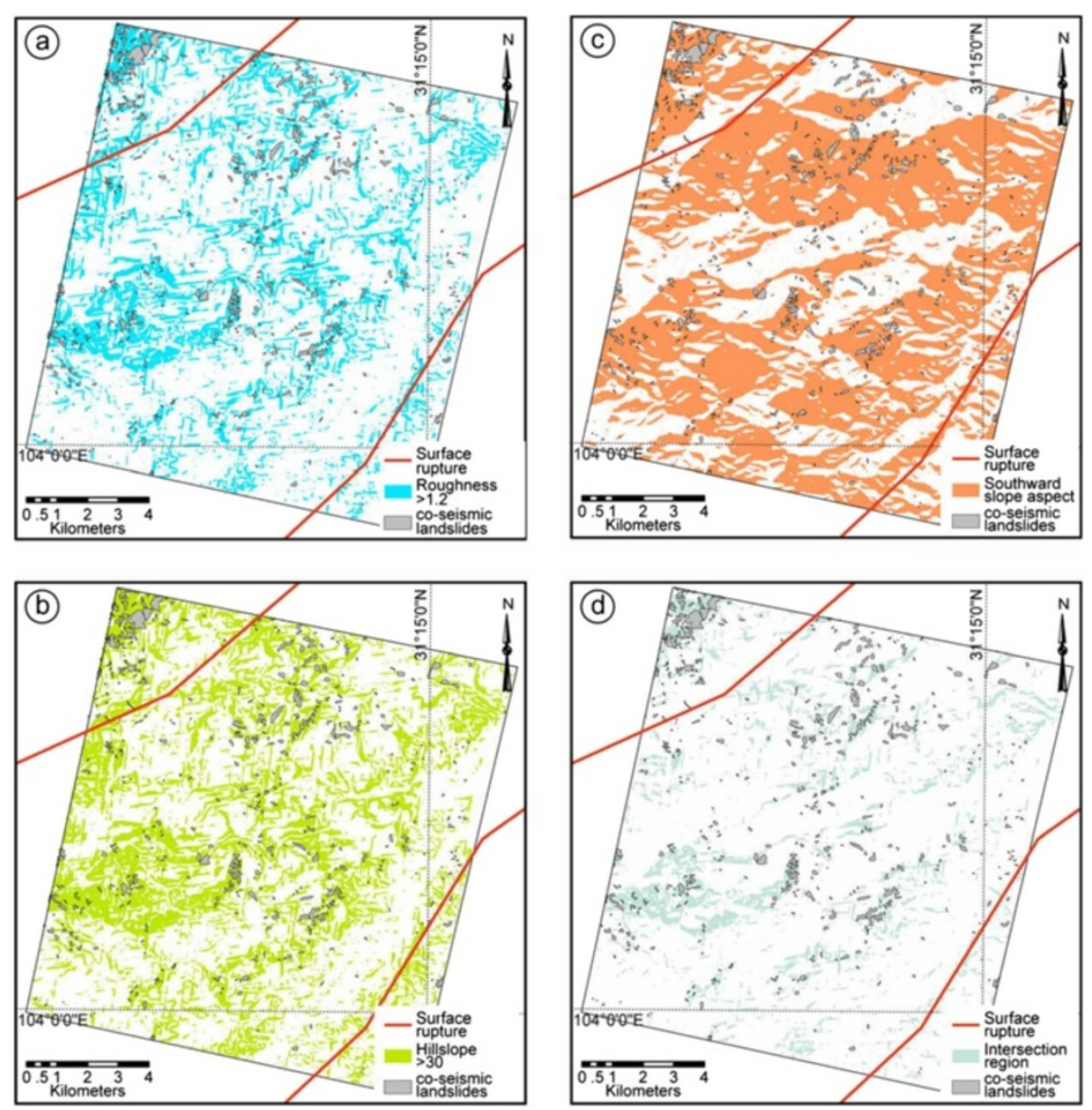

Figure 4 Topographic features of Site III. The roughness (a), hillslope (b), slope aspect (c) distribution of Site III based on pre-earthquake DEM data; and the intersection region of the above three regions (d) by applying thresholds $>1.2$, between 90 and 270, and 30 .

influence on the landslide possibility due to the differences of temperature, sediment condition, vegetation etc. (e.g. Rech et al. 2001; Fekedulegn et al. 2003). Mechanical, chemical and biological weathering are much stronger on the southward facing slopes than that on the northward facing slopes, where are more open to the sunlight and warm wind. The slope aspect analysis on post-earthquake DEM also shows high landslide density on the southward facing slopes (Figures 2, 3 and 4). The southward slope aspect is generally between 90 and 270 degree. Therefore, applying threshold value of 90-270, we can derive the landslide potential area on the basis of the slope aspect analysis. According to the slope aspect, post-earthquake slope aspect did not change much, comparing with preearthquake data within the landslide area. It indicates that the co-seismic landslides did not affect the slope aspect, i.e., it is not controlled by such tectonic events.

\section{Seismic information}

According to the co-seismic landslides, seismic information such as ground motion is one of the main trigger mechanisms. We consequently analyzed the characteristics of landslide areas based on multiple approaches including ground motion information.

Preliminary analyses of the strong motion records show that the peak ground acceleration (PGA) contours distribute in the region peripheral to the co-seismic surface rupture with the maximum value of 957.7 gal ( $\mathrm{Li}$ et al. 2008; Figure 6). We collected the strong motion records of 267 stations in the regions affected by Wenchuan earthquake. The PGA maps of the UD (up-down) and horizontal (combination of north-south and east-west) vectors, respectively, show close relation with the co-seismic surface rupture zone (Figure 6(a) and (b)). Previous studies have demonstrated that PGA also could be used as a threshold to evaluate landslide susceptibility (Harp and Wilson 1995; Murphy et al. 2002; Meunier et al. 2007; Wang et al. 2011). Recent study suggests that the co-seismic landslide of the Wenchuan earthquake is closely related to the PGA value (Wang et al. 2011). The co-seismic landslides are also directly controlled by the geological structures such as the co-seismic surface ruptures. Previous 

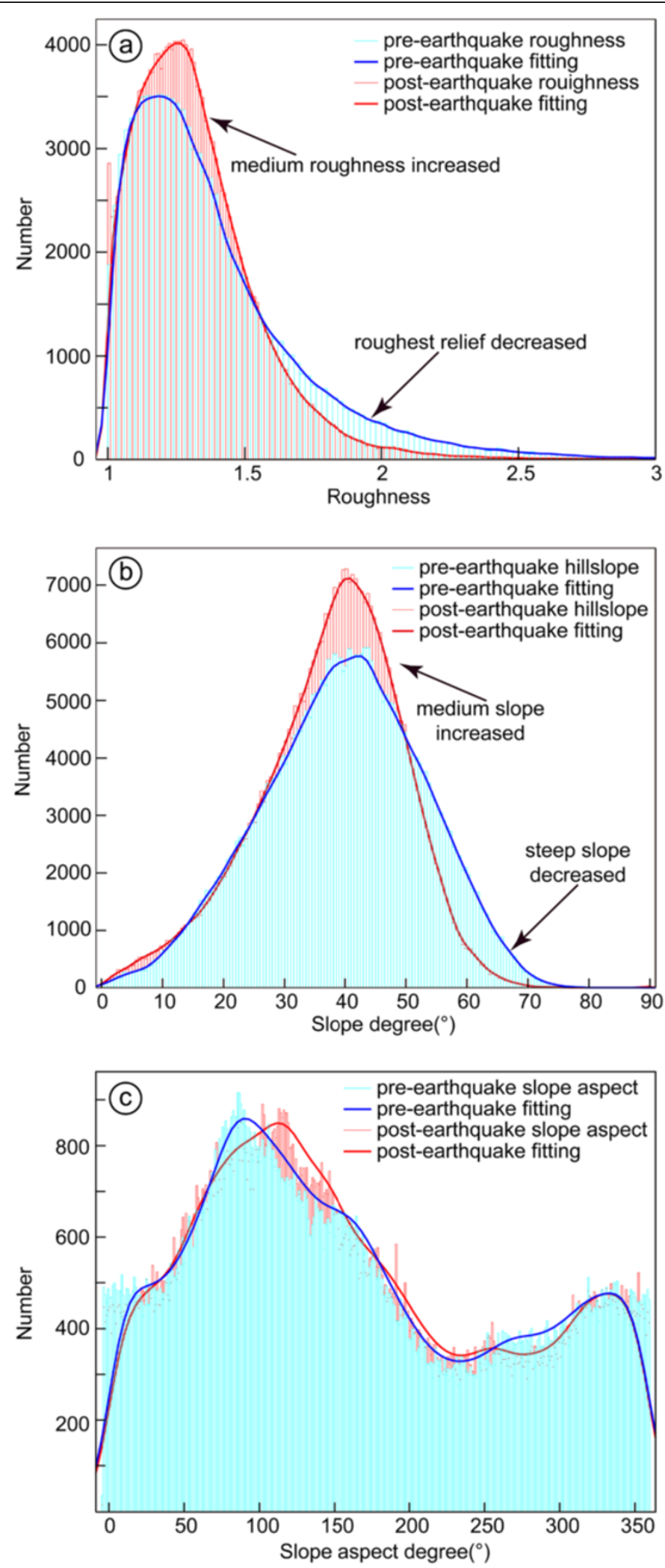

Figure $\mathbf{5}$ Co-seismic topographic changes. Distribution of Pre-earthquake and post-earthquake hillslope (a), roughness (b) and slope aspect (c). The medium topography are roughened and steepened, however the steepest and roughest topography are smoothed by the Wenchuan earthquake. The slope aspect is almost unchanged. 
Table 4 Topographic analysis of the co-seismic landslides produced by the 2008 Wenchuan earthquake

\begin{tabular}{|c|c|c|c|}
\hline & LD & IAD & EALD \\
\hline \multicolumn{4}{|l|}{ Site I } \\
\hline Slope aspect & $51.73 \%$ & $45.46 \%$ & $23.52 \%$ \\
\hline Roughness & $56.72 \%$ & $54.10 \%$ & $30.68 \%$ \\
\hline Slope & $67.33 \%$ & $41.85 \%$ & $28.18 \%$ \\
\hline Intersection & $30.55 \%$ & $100 \%$ & $30.55 \%$ \\
\hline \multicolumn{4}{|l|}{ Site ॥ } \\
\hline Slope aspect & $50.34 \%$ & $69.31 \%$ & $34.89 \%$ \\
\hline Roughness & $75.96 \%$ & $53.89 \%$ & $40.94 \%$ \\
\hline Slope & $82.85 \%$ & $47.46 \%$ & $39.32 \%$ \\
\hline Intersection & $38.34 \%$ & $100 \%$ & $38.34 \%$ \\
\hline \multicolumn{4}{|l|}{ Site III } \\
\hline Slope aspect & $66.50 \%$ & $20.77 \%$ & $13.81 \%$ \\
\hline Roughness & $46.90 \%$ & $56.57 \%$ & $33.04 \%$ \\
\hline Slope & $58.42 \%$ & $36.79 \%$ & $17.25 \%$ \\
\hline Intersection & $34.14 \%$ & $100 \%$ & $34.14 \%$ \\
\hline \multicolumn{4}{|c|}{$\begin{array}{l}\text { LD: Landslide density: landslides occurred within the derived regions based on } \\
\text { topographic analysis of roughness, hill slope and slope aspect by applying } \\
\text { corresponding thresholds (detail thresholds refer to the text); IAD: intersection } \\
\text { area density, represents the area percentage of the intersection area within } \\
\text { the derived regions; EALD: Equal area landslide density, by multiple the } \\
\text { landslide percentage with the intersection area percentage which is used to } \\
\text { describe the efficiency of each method in landslide occurrence detection. }\end{array}$} \\
\hline
\end{tabular}

study has demonstrate the significant hanging wall effect (Ren and Lin 2010), thus according to thrust fault, landslide occurrence will mainly occupy the hanging wall side. The co-seismic landslides triggered by the Wenchuan earthquake mainly occurred on the hanging wall side where confined by the up-down and horizontal PGA contour of 150 gal and 200 gal, respectively (Figure 6(a) and (b)).

\section{Discussion}

Co-seismic landslide is a kind of special landslide directly triggered by strong earthquake (Harp and Jibson 1996; Gallousi and Koukouvelas 2007; Owen et al. 2008; Ren and Lin 2010; Dai et al. 2011a). Therefore, the co-seismic landslides are related to the topographic situation and seismic shaking. In landslide-related studies, roughness, hillslope and slope aspect analyses are the most widely used methods in geomorphologic studies (Dai and Lee 2002; Casson et al. 2005; Ren and Lin 2010; Korup et al. 2007; Chuang and Fabbri 2008). After the 2008 Mw 7.9 Wenchuan earthquake, there are numerous co-seismic landslides were triggered (Ren and Lin 2010; Yin et al. 2010, Godard et al. 2010; Ouimet 2010; Dai et al. 2011a, $2011 b)$, which provide an ideal opportunity to check the co-seismic landslides characters. Based on the preearthquake DEM data, we can analysis the topographic character of the landslided area. Comparing pre-
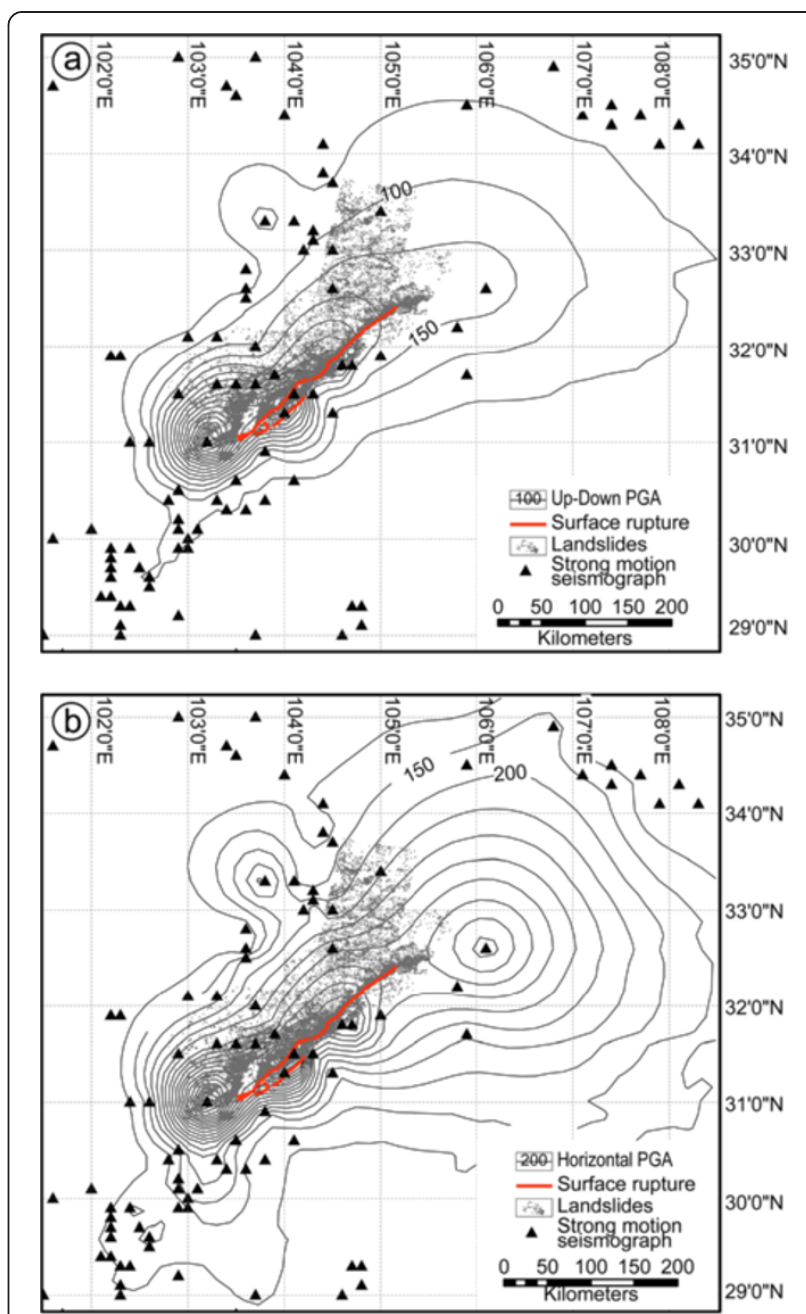

Figure 6 Relationship between PGA and distribution of co-seismic landslides. Up-down PGA (a) and horizontal PGA (b) contours with the distribution of co-seismic landslides produced by the Wenchuan earthquake.

earthquake and post-earthquake DEM data, we can consequently analysis the topographic effects of the Wenchuan earthquake. In order to derive the high landslide density region, the threshold values of roughness, hillslope and slope aspect are set to be $>1.2,>30$, and between 90 and 270, respectively.

Landslide occurrence shows clearly correlation with the topographic conditions. At all the three sites, over $50 \%$ landslides occurred in the derived roughness, aspect and hillslope areas over the threshold values, respectively (Table 4). In order to evaluate the actual correlation between the above topographic parameters and landslide occurrence, we apply equal landslide density as the main factor. Equal landslide density is the ratio between the landslide areas and the corresponding areas derived by applying the roughness, hillslope and slope aspect thresholds. Among the three parameters, roughness is 
closely correlated to landslide rather than hillslope, i.e., the highest equal area landslide density. The intersection regions are derived from the intersection regions of the roughness, hillslope and slope aspect areas by applying the above thresholds. Therefore, the areas decreased significantly and the landslides occurred in the intersection region is lower than $40 \%$. However, the intersection region is only $20-69 \%$ of the areas derived from roughness, hillslope, and slope aspect map. Consequently, the equal area density of the co-seismic landslide is still the highest. The geological structure of Longmen Shan Thrust Belt and seismic shake information of PGA data both suggest that the co-seismic landslides mainly occurred in regions within the up-down and horizontal PGA contour of 150 and 200 gal on the hanging wall side (Figure 6).

Post-earthquake DEM analysis indicates the medium roughness and hillslope regions are becoming rougher and steeper after the Wenchuan earthquake. The roughest relief and steepest slopes are smoothed by the Wenchuan earthquake (Figure 5). This indicates that the medium topographic roughness and hillslope are modified by the Wenchuan-like strong earthquakes or landslides. However, slope aspect did not change much, which indicates the formation and modification of slope aspect is not directly related to single tectonic events such as strong earthquake or landslide. The roughest and steepest regions are co-seismically smoothed by the Wenchuan earthquake. Thus, rough and steep regions are difficult to stand for a long geological epoch with repeated strong earthquakes. Previous studies have demonstrated that landslides have played an important role in the surface processes in Longmen Shan region (Meng et al. 2006). Consequently, our results indicate that the co-seismic landslides are controlled both by topographic conditions and ground motion. The strong earthquakes play an important role in local topographic formation and modification by triggering co-seismic landslides.

\section{Conclusions}

Based on the data and analyses of the present study, we arrived at the following conclusions.

1) Collaborative topographic analyses are efficient in landslide susceptibility evaluation. The co-seismic landslides are related to the topographic roughness, hillslope and slope aspect. The topographic thresholds are $>1.2$, between 90 and 270, and 30, respectively. The co-seismic landslides are also directly related to PGA values, which is usually occurred on hanging wall within the up-down and horizontal PGA contour of 150 and 200 gal, respectively.

2) Topographic conditions such as roughness and hillslope are controlled by tectonic event like the
Wenchuan earthquake, however, slope aspect is not modified by such event.

3) The roughest relief and steepest slope regions were smoothed after the Wenchuan earthquake, however the medium roughness and slope regions became rougher and steeper, respectively.

\section{Competing interests}

The authors declare that they have no competing interests.

\section{Authors' contributions}

RZK constructed the proposed framework as well as wrote the manuscript. RZK and ZZQ make the topographic and statistical analysis. DFC and YJH provide the important landslide distribution data. ZHP give valuable suggestions in the topographic analysis. All authors read and approved the final manuscript.

\section{Acknowledgments}

We thank Qiang Xu, Weili Li and Tao Chen for helpful comments and discussion. This work was funded by the National Nonprofit Fundamental Research Grant of China (IGCEA1119), Foundation of Returned Overseas Scholars of China and National Natural Science Foundation of China (41102136).

\section{Author details}

${ }^{1}$ State Key Laboratory of Earthquake Dynamics, Institute of Geology, China Earthquake Administration, Beijing 100029, China. ${ }^{2}$ Institute of Geology and Geophysics, Chinese Academy of Sciences, P.O. Box 9825, Beijing 100029, P R. China.

Received: 14 August 2013 Accepted: 14 October 2013 Published: 17 October 2013

\section{References}

Burbank DW, Leland J, Fielding E, Anderson RS, Brozovic N, Reid MR, Duncan C (1996) Bedrock incision, rock uplift and threshold hillslopes in the northwestern Himalayas. Nature 379:505-510

Burchfiel BC, Chen Z, Liu Y, Royden LH (1995) Tectonics of the Longmen Shan and adjacent regions, Central China. Int Geol Rev 37:661-735

Burchfiel BC, Royden LH, van der Hilst RD, Hager BH, Chen Z, King RW, Li C, Lu J, Yao H, Kirby E (2008) A geological and geophysical context for the Wenchuan earthquake of 12 May 2008, Sichuan, People's Republic of China. GSA Today 18:4-11

Casson B, Delacourt C, Allemand P (2005) Contributino of multi-temporal remote sensing images to characterize landslide slip surface-Application to the La Clapiere landslide (France). Nat Hazards Earth Syst Sci 5:425-437

Chen SF, Wilson CJL (1996) Emplacement of the Longmen Shan Thrust-Nappe belt along the eastern margin of the Tibetan plateau. J Struct Geol 18 (4):413-430

Chen Z, Burchfiel BC, Liu Y, King RW, Royden LH, Tang W, Wang E, Zhao J, Zhang $X$ (2000) Global Positioning System measurements from eastern Tibet and their implications for India/Eurasia intercontinental deformation. J Geophys Res 105(B7):16215-16227

Chuang CJ, Fabbri AG (2008) Predicting landslides for risk analysis-Spatial models tested by a cross-validation technique. Geomorphology 94:438-452

Dai F, Lee C (2002) Landslide characteristics and slope instability modeling using GIS, Lantau Island, Hong Kong. Geomorphology 42:213-228

Dai F, Xu C, Yao X, Xu L, Tu X, Gong Q (2011a) Spatial distribution of landslides triggered by the 2008 Ms 8.0 Wenchuan earthquake, China. J Asian Earth Sci 40:883-895

Dai F, Tu X, Xu C, Gong Q, Yao X (2011b) Rock avalanches triggered by oblique-thrusting during the 12 May 2008 Ms8.0 Wenchuan earthquake, China. Geomorphology 132:300-318

Densmore AL, Ellis MA, Anderson RS (1998) Landsliding and the evolution of normal-fault-bounded mountains. J Geophys Res 103:15203-15219

Densmore AL, Ellis MA, Li Y, Zhou R, Handcock GS, Richardson N (2007) Active tectonics of the Beichuan and Pengguan faults at the eastern margin of the Tibetan Plateau. Tectonics 26:TC4005. doi:10.1029/2006TC001987 
Fekedulegn D, Hicks RR, Colber JJ (2003) Influence of topographic aspect, precipitation and drought on radial growth of four major tree species in an Appalachian watershed. For Ecol Manage 177:409-425

Gallousi C, Koukouvelas IK (2007) Quantifying geomorphic evolution of earthquake-triggered landslides and their relation to active normal faults. An example from the Gulf of Corinth, Greece. Tectonophysics 440:85-104

Gan WJ, Zhang P, Shen Z, Niu Z, Wang M, Wan Y, Zhou D, Cheng J (2007) Present-day crustal motion within the Tibetan Plateau inferred from GPS measurements. J Geophys Res-Sol Earth 112:B08416. doi:10.1029/2005JB004120

Godard V, Lave J, Carcaillet J, Cattin R, Bourles D, Zhu J (2010) Spatial distribution of denudation in Eastern Tibet and regressive erosion of plateau margins. Tectonophysics 491:253-274

Harp EL, Jibson RW (1996) Landslides triggered by the 1994 Northridge, California, Earthquake. Bull Seismol Soc Am 86:S319-S332

Harp EL, Wilson RC (1995) Shaking intensity thresholds for rock falls and slides: Evidence from 1987 Whittier Narrows and superstition hills earthquake strong-motion records. Bull Seismol Soc Am 85:1739-1757

Hovius N, Meunier P, Lin C, Chen H, Chen Y, Dadson S, Ming-Jame H, Lines M (2011) Prolonged seismically induced erosion and the mass balance of a large earthquake. Earth Planet Sci Lett. doi:10.1016/j.epsl.2011.02.005

Jibson RW, Harp EL, Michael JA (2000) A method for producing digital probabilistic seismic landslide hazard maps. Eng Geol 58:271-289

King RW, Shen F, Burchfiel BC, Royden LH, Wang E, Chen Z, Liu Y, Zhang X, Zhao J, Li Y (1997) Geodetic measurements of crustal motion in southwest China. Geology 25:179-182

Korup O, Clague JJ, Hermanns RL, Hewitt K, Strom AL, Weidinger JT (2007) Giant landslides, topography, and erosion. Earth Planet Sci Lett 261:578-589

Li X, Zhou Z, Huang M, Wen R, Yu H, Lu D, Zhou Y, Cui J (2008) Preliminary analysis of strong-motion recordings from the magnitude 8.0 Wenchuan, China, Earthquake of 12 May 2008. Seismol Res Lett 79:844-854. do: $10.1785 /$ gssrl.79.6.844

Lin A, Ren Z, Jia D, Wu X (2009) Co-seismic thrusting rupture and slip distribution produced by the 2008 Mw7.9Wenchuan earthquake, China. Tectonophysics. doi:10.1016/j.tecto.2009.02.014

Lin A, Rao G, Yan B (2012) Field evidence of rupture of the Qingchuan Fault during the $2008 \mathrm{Mw} 7.9$ Wenchuan earthquake, northeastern segment of the Longmen Shan Thrust Belt. Tectonophysics:522-523. 243-252, doi:10.1016/j. tecto.2011.12.012

Liu-Zeng J, Zhang Z, Wen L, Tapponnier P, Sun J, Xing X, Hu G, Xu Q, Zeng L, Ding L, Ji C, Hudnut KW, van der Woerd J (2009) Co-seismic ruptures of the 12 May 2008, Ms 8.0 Wenchuan earthquake, Sichuan: East-west crustal shortening on oblique, parallel thrusts along the eastern edge of Tibet. Earth Planet Sci Lett 286:355-370. doi:10.1016/j.epsl.2009.07.017

Mackey BH, Roering JJ (2011) Sediment yield, spatial characteristics, and the long-term evolution of active earthfl ows determined from airborne LiDAR and historical aerial photographs, Eel River, California. Geol Soc Am Bull. doi:10.1130/B30306.1.1

Meng Q, Hu J, Wang E, Qu H (2006) Late Cenozoic denudation by large-magnitude landslides in the eastern edge of Tibetan Plateau. Earth Planet Sci Lett 243:252-267

Meunier P, Hovius N, Haines AJ (2007) Regional patterns of earthquake-triggered landslides and their relation to ground motion. Geophys Res Lett 34:L20408. doi:10.1029/2007GL031337

Murphy W, Petly DN, Bommer J, Mankelow JM (2002) Uncertainty in ground motion estimates for the evaluation of slope stability during earthquakes. Q J Eng Geol Hydroge 35:71-78

Ouimet WB (2010) Landslides associated with the May 12, 2008 Wenchuan earthquake: Implications for the erosion and tectonic evolution of the Longmen Shan. Tectonophysics 491:244-252

Owen LA, Kamp UK, Khattak GA, Harp EL, Keefer DK, Bauer MA (2008) Landslides triggered by the 8 October 2005 Kashmir earthquake. Geomorphology 94:1-9

Parker RN, Densmore AL, Rosser NJ, de Michele M, Li Y, Huang R, Whadcoat S, Petley DN (2011) Mass wasting triggered by the 2008 Wenchuan earthquake is greater than orogenic growth. Nat Geosci. doi:10.1038/NGEO1154

Rech JA, Reeces RW, Hendricks DM (2001) The influence of slope aspect on soil weathering processes in the Springerville volcanic field, Arizona. Catena 43:49-62

Ren Z, Lin A (2010) Co-seismic landslides induced by the 2008 Wenchuan magnitude 8.0 earthquake, as revealed by ALSO PRISM and AVNIR2 imagery data. Int J Remote Sens 31:3479-3493
Tang C, Zhu J, Qi X, Ding J (2011) Landslides induced by the Wenchuan earthquake and the subsequent strong rainfall event: A case study in the Beichuan area of China. Eng Geol 122:22-33

Tao CV, Hu Y (2001) A comprehensive study of the rational function model for photogrammetric processing. Photogramm Eng Remote Sens 67:1347-1357

Wang X, Nie G, Wang S (2011) Ground motion acceleration criterion for judging landslide induced by the 2008 Wenchuan earthquake. Acta Seismologica Sinica 33:82-90

Xu X, Wen X, Yu G, Chen G, Klinger Y, Hubbard J, Shaw J (2009) Coseismic reverse- and oblique-slip surface faulting generated by the $2008 \mathrm{Mw} 7.9$ Wenchuan earthquake, China. Geology 37:515-518

Yin J, Chen J, Xu X, Wang X, Zheng Y (2010) The characteristics of the landslides triggered by the Wenchuan Ms 8.0 earthquake from Anxian to Beichuan. J Asian Earth Sci 37:452-459

Zhang P, Shen Z, Wang M, Gan W, Burgmann R, Molnar P, Wang Q, Niu Z, Sun J, Wu J, Sun H, You X (2004) Continuous deformation of the Tibetan Plateau from Global Positioning System data. Geology 32:809-812. doi:10.1130/G20554.1

Zhang P, Wen X, Shen Z, Chen J (2010) Oblique, high-angle, listric-reverse faulting and associated development of strain: the Wenchuan earthquake of May 12, 2008, Sichuan, China. Ann Rev Earth Planetary Sci 38:353-382

Zhang HP, Zhang P, Kirby E, Yin J, Liu C, Yu G (2011) Along-strike topographic variation of the Longmen Shan and its significance for landscape evolution along the eastern Tibetan Plateau. J Asian Earth Sci 40(4):855-864

Zhou R, Li Y, Densmore AL, Ellis MA, He Y, Li Y, Li X (2007) Active tectonics of the Longmen Shan region of the eastern margin of the Tibetan plateau. Acta Geologica Sinica 81:593-604

doi:10.1186/2193-1801-2-544

Cite this article as: Ren et al: Co-seismic landslide topographic analysis based on multi-temporal DEM-A case study of the Wenchuan earthquake. SpringerPlus 2013 2:544

\section{Submit your manuscript to a SpringerOpen ${ }^{\circ}$ journal and benefit from:}

- Convenient online submission

- Rigorous peer review

- Immediate publication on acceptance

- Open access: articles freely available online

- High visibility within the field

- Retaining the copyright to your article

Submit your next manuscript at $\gg$ springeropen.com 